UDC $534.1+517.988$

\author{
V.P. Legeza*, O.V. Atamaniuk \\ Igor Sikorsky Kyiv Polytechnic Institute, Kyiv, Ukraine \\ *corresponding author: viktor.legeza@gmail.com
}

\title{
THE BRACHISTOCHRONIC MOVEMENT OF A MATERIAL POINT IN THE HORIZONTAL VECTOR FIELD OF A MOBILE FLUID
}

\begin{abstract}
Background. Since the brachistochronic motion of a material point in a flat vector field of a mobile fluid was not previously considered, the formulated variational problem of searching for extremal trajectories in such a formulation is new and relevant.

Objective. The aim of the study is to obtain the algebraic equations of extremal trajectories of motion, along which the material point moves from a given starting point to a given finish point in the shortest possible time.

Methods. The solution of the problem was carried out using classical methods of the calculus of variations (to obtain a differential equation for the motion of a material point), as well as using Taylor series (for approximate integration of the resulting differential equation). For a given variant of the boundary conditions, approximate algebraic equations of extremals of the motion of a material point were established in the form of segments of power series. A comparative analysis of the time of movement was carried out both along extreme trajectories and along an alternative shortest path - along a straight line, which connects two given points of start and finish.

Results. It is shown that the considered variational problem has two different solutions, which differ only in sign. At the same time, only one solution provides the minimum time for the movement of a material point between the given start and finish points. Studies have also found that the extremal trajectory of the brachistochronic movement of a point is not straight and has an oscillatory character.

Conclusions. The proposed approach allows plotting in advance such a logistical route of a material point (motorboat) in a flat vector field of a mobile fluid between the given start and finish points, which ensures the minimum travel time between them. In this case, the extremal trajectory will not necessarily be the shortest line that connects the start and finish points.
\end{abstract}

Keywords: variational problem; brachistochronic motion; vector field of a mobile fluid; time functional; Euler equation; boundary conditions; Taylor series; extremal trajectory.

\section{Introduction}

First, we will present a summary of recent research carried out in the framework of the calculus of variations, and related to the search for the brachistochrone equations in various problem statements.

In paper [1] the problem of J. Bernoulli on the brachistochrone is analytically and numerically solved in the most general case, taking into account both viscous and dry friction. It is proved that in the absence of friction forces, any movement along a curved chute under the influence of gravity alone and under the condition of minimal movement time is always reduced to the brachistochrone problem and the solution can be found without using the methods of variation calculus, and using only the general laws of curvilinear motion dynamics. The solution of the classical Bernoulli problem is found, but under the condition that the length of the trajectory is fixed. It is shown that under this isoperimetric condition the class of trajectories will be very different from the classical brachistochrone.

In papers [2-5] the problem of maximizing the horizontal coordinate of a point moving in a vertical plane under the action of gravity, viscous friction and accelerating forces, and the brachistochrone problem interrelated with it are considered. The optimal control problem is reduced to a boundary one for a system of two nonlinear differential equations. A synthesis of extremal control was constructed, which made it possible to investigate the problem using methods of the theory of dynamic systems. The analysis clarifies the analytical results and allows you to justify the results of computer simulation obtained by other authors.

Papers [6-8] briefly highlight the provisions of A.S. Vondrukhov's thesis "Brahistochrone under the action of accelerating force, as well as dry and viscous friction". Explicitly obtained formula, presented depending on the speed, which provides a synthesis of optimal control for the case of action on the point of dry and viscous friction, as well as 
accelerating strength. A study has been carried out on the properties of optimal trajectories for the action of separately dry or viscous friction, which makes it possible to create an idea of the shape of optimal trajectories. A system of differential equations with an additional variable is obtained, which allows one to construct optimal trajectories by solving the Cauchy problem.

Paper [9] considers the classical problem of finding the plane material frictionless curve along which a heavy particle released from the starting position reaches the given finish position as quickly as possible. Johann Bernoulli proposed the name "brachistochrone" for the desired curve. Over a hundred publications are devoted to generalizations of the classical problem. The work gives a classification of these generalizations with a bibliographic selection of relevant literature. The recent results of the solution of the generalized problem in the presence of dry (Coulomb) friction are considered.

Article [10] in an accessible form gives a geometric interpretation of the brachistochrone problem, which requires only the basic properties of triangles, and as a result a cycloid is obtained. Geometry also shows that Cycloid is Huygens' tautochron.

Article [11] provides an overview of the research on the brachistochrone, initiated by Johann Bernoulli in 1696-1697. As is known, its solution is a cycloid. The author follows Bernoulli's optical solution, based on the Fermat principle of the shortest time, and later paraphrases it in terms of the Hamilton article of 1828. Hamilton's solution restores cycloid in the same way that Newton's mathematical principles imply Kepler's laws.

In papers $[13,14]$, the dynamics of systems with dampers of low-frequency oscillations are considered, in the construction of which a transcendental surface is used, formed by brachistochrone for a rolling body of finite size (cylinder, ball). The use of such devices allows you to keep the oscillation frequency of the rolling body constant regardless of the magnitude of the amplitude of its oscillations.

The book [15] presents a course of lectures on classical calculus of variations, as well as a more modern development of the theory of optimal control from the point of view of an applied mathematician. Moreover, to solve variational problems (including the brachistochrone problem), as well as for the graphic representation of research results. Math application packages such as Maple Mathematica, MATLAB are widely used.
Article [16] presents the problem of the fastest descent, or the Brachistochrone curve, which can be solved using the calculus of variations and the Euler-Lagrange equation. Cycloid is the fastest curve, and also has the property of isochronism, thanks to which Huygens perfected the Galilean pendulum.

In papers $[12,17-20]$, the problems of the brachistochronic motion of various objects (the material point of variable mass, the vertical disk, the Chaplygin sleigh with a non-holonomic coupling), in arbitrary force fields are solved within the framework of the Pontryagin maximum principle and the singular theory of optimal control. As a result, these tasks are reduced to the corresponding two-point boundary value problems. Their solutions are implemented using the numerical procedure of the shooting method.

In paper [21], the problem of the brachistochronic motion of a material point is considered, taking into account to the Coulomb forces of dry friction, and is formulated as a variational isoperimetric problem. The parametric equations of the extremal curve are obtained. If a solution to this problem exists, then this curve is the desired brachistochrone.

In the present work, a new brachistochrone problem is considered for the case of the motion of a material point in a horizontal one-dimensional vector field of a mobile fluid.

\section{Problem statement}

A new variational problem on the motion of a material point in a one-dimensional horizontal vector field between two given points in the shortest time is considered.

Geometric and kinematic relations. Let a motorboat (considered in this problem as a material point) cross a turbulent river with a channel width $L$ starting from one bank at the point $O(0,0)$ and finishing on the opposite bank at a point $M(L, y(L))$. For the subsequent reasoning, it is convenient to introduce a rectangular Cartesian coordinate system as it is done in Fig. 1.

Axis $O X$ will be directed horizontally to the right, axis $O Y$ - vertically upwards. The intersection of these axes determines the origin of coordinates $O$, the same point is the starting point of the boat. Let us mark the opposite bank of the river $M L$, and $M L \| O Y$.

The boat moves at a speed $\vec{C}$ whose modulus $C$ is constant and is determined by the formula: 


$$
\sqrt{u^{2}+v^{2}}=C,
$$

where $u$ is a horizontal projection of the speed of the boat; $v$ is a vertical projection of the speed of the boat. The projections of $u$ and $v$ are continuous functions of $x, x \in[0, L]$. The speed vector $\vec{C}$ of the boat is directed along the tangent, built at the current point of its position on the desired trajectory $y=y(x)$. Consider the functions $y(x)$ that belong to space $C^{1}[0, L]$.

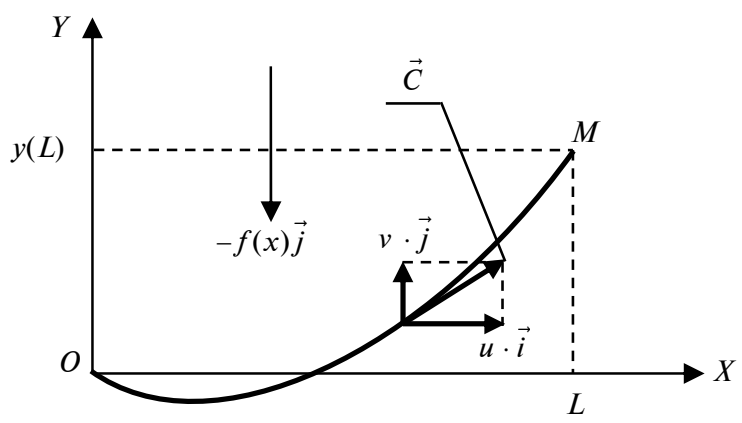

Fig. 1. One of the possible trajectories of the motion of the boat in the chosen coordinate system $O X Y: f(x)$ is the speed of the flow of the river; $u$ is the horizontal projection of the speed of the boat; $v$ is the vertical projection of the speed of the boat

Here it should be noted that despite the module $C$ of the speed of the boat is constant, its projections $u$ and $v$ on the coordinate axes are variables. In this study, the velocity of the river is specified as a function of the horizontal coordinate $f(x)$, and the velocity vector is directed in the opposite direction with respect to the ort of the axis $O Y$. Thus, the river velocity vector has the form: $V_{\text {riv }}=-f(x) \vec{j}$. We assume that in the vertical direction (along the axis $O Z$ ) the weight of the boat is balanced by the buoyancy force of Archimedes, and, therefore, the boat does not move in this direction.

Physically, the motion of the boat can be identified with the motion of a material point in a one-dimensional horizontal vector field of velocities $\vec{B}$ of a fluid, each point of which moves in one plane (in this case $z=0$ ) colinearly orth of the axis $O Y$. In this case, the vector can be written as follows: $\vec{B}=(0 ;-f(x) ; 0)$. The resistance of the fluid during the movement of the boat is taken proportional to the corresponding components of the velocity of the material point (boat) and it is already taken into account in the variables $u$ and $v$.

Purpose of the study: it is necessary to obtain the algebraic equations $y=y(x)$ of extremal trajectories of motion, along which the material point (boat) moves from a given starting point to a given finish point in the shortest possible time.

The construction of the time functional and definition of an equation of the desired trajectory. First, we consider the task in the general case, that is, for function $f(x)$ of a general form. After that, we will select a specific function $f(x)$ and determine the trajectory of the boat movement corresponding to it. We write expressions for the projections of the speed of the boat on axis $O X$ and $O Y$ taking into account the speed of the flow of the river:

$$
\left\{\begin{array}{l}
\frac{d x}{d t}=u ; \\
\frac{d y}{d t}=v-f(x) .
\end{array}\right.
$$

We write the time functional that needs to be minimized:

$$
\begin{gathered}
T=\int_{0}^{L} \frac{d x}{u} \rightarrow \min _{y(x)}, \\
u(x) \in C^{0}[0, L] ; y(x) \in C^{1}[0, L] .
\end{gathered}
$$

We use the system of equations (2) to construct the integrand of functional (3). We divide the second equation of system (2) by the first:

$$
\frac{d y}{d x}=\frac{v}{u}-\frac{f(x)}{u} .
$$

Using relation (1), we define the expression for the fraction:

$$
\frac{v}{u}=\sqrt{\left(\frac{C}{u}\right)^{2}-1} .
$$

Substituting relation (5) into equation (4) we obtain a quadratic equation with respect to the unknown variable $z=\frac{1}{u}$ :

$$
\left[f^{2}(x)-C^{2}\right] z^{2}+2 y^{\prime}(x) f(x) z+\left(y^{\prime 2}(x)+1\right)=0 .
$$

This equation has the following solutions:

$$
z_{1,2}=\left(\frac{1}{u}\right)_{1,2}=\frac{-f(x) y^{\prime} \pm \sqrt{\left(C y^{\prime}\right)^{2}-\left(f^{2}(x)-C^{2}\right)}}{f^{2}(x)-C^{2}} .
$$


Substitute expression (6) in functional (3):

$T=\int_{0}^{L} \frac{-f(x) y^{\prime} \pm \sqrt{\left(C y^{\prime}\right)^{2}-\left(f^{2}(x)-C^{2}\right)}}{f^{2}(x)-C^{2}} d x$.

We write the integrand function in functional (7):

$$
F\left(x, y^{\prime}\right)=\frac{-f(x) y^{\prime} \pm \sqrt{\left(C y^{\prime}\right)^{2}-\left(f^{2}(x)-C^{2}\right)}}{f^{2}(x)-C^{2}} .
$$

We use the Euler equation [15] to build a differential equation for the desired trajectory of the boat:

$$
F_{y}^{\prime}-\frac{d}{d x}\left(F_{y^{\prime}}^{\prime}\right)=0 .
$$

Since function (8) does not depend on variable $y$, we have here $F_{y}^{\prime}=0$. As a result, Euler's equation (9) is reduced and transformed into a first order differential equation:

$$
\frac{d}{d x}\left(F_{y^{\prime}}^{\prime}\right)=0 \text {, or, } F_{y^{\prime}}^{\prime}=C_{1},
$$

where $C_{1}$ is the first arbitrary constant.

Now we can determine the differential equation of the trajectory of the boat:

$$
\pm \frac{C^{2} y^{\prime}}{\sqrt{\left(C y^{\prime}\right)^{2}-\left(f^{2}(x)-C^{2}\right)}}=C_{1} \cdot\left(f^{2}(x)-C^{2}\right)+f(x)
$$

or

$$
\begin{gathered}
\frac{C^{4}\left(y^{\prime}\right)^{2}}{\left(C y^{\prime}\right)^{2}-\left(f^{2}(x)-C^{2}\right)} \\
=\left[C_{1} \cdot\left(f^{2}(x)-C^{2}\right)+f(x)\right]^{2} .
\end{gathered}
$$

Further, derivative $y^{\prime}$ is expressed from equation (11):

$$
y^{\prime}= \pm \frac{1}{C} \sqrt{\frac{f^{2}(x)-C^{2}}{1-\frac{C^{2}}{\left[C_{1} \cdot\left(f^{2}(x)-C^{2}\right)+f(x)\right]^{2}}}} .
$$

After integration, we obtain an equation of the desired curve - brachistochrone - in the studied movement of the material point (boat):

$$
y(x)= \pm \frac{1}{C} \int \sqrt{\frac{f^{2}(x)-C^{2}}{C^{2}}} d x+C_{2},
$$

where $C_{2}$ is the second arbitrary constant.
Formula (13) establishes the final form of the equation of the desired curve, to which two boundary conditions of this variational problem should be attached:

$$
y(0)=0 ; y(L)=y_{L} .
$$

\section{A specific example and its numerical implemen- tation}

Now consider this task, provided that a specific function $f(x)$ is set, that determines the speed of the river at each point of axis $O X$, namely

$$
f(x)=\sin \left(\frac{\pi x}{L}\right)
$$

Substitute the given function (15) into the general expression of the differential equation of curve (13). All intermediate transformations that were performed above for function $f(x)$ of a general form are not given for this function. After some transformations we get:

$$
y= \pm \int g\left(x, C, C_{1}\right) d x+C_{2},
$$

where $g\left(x, C, C_{1}\right)=\frac{\left[C_{1} \cdot\left(f^{2}(x)-C^{2}\right)+f(x)\right]}{C}$

$$
\times \sqrt{\frac{C^{2}-f^{2}(x)}{C^{2}-\left[C_{1} \cdot\left(f^{2}(x)-C^{2}\right)+f(x)\right]^{2}}} .
$$

First, we see that the variational problem has two different solutions, which correspond to each of the two signs before integral (16). Secondly, integral (16) is not taken in closed form. Therefore, we integrate it numerically, by representing integrand $g\left(x, C, C_{1}\right)$ in the form of a truncated Taylor series in a variable $x$ in a neighborhood of a point $x=0$. To achieve the required accuracy, we limit ourselves to six terms of the Taylor series and, omitting the intermediate transformations, we immediately write down the necessary expressions for derivatives $g^{(0)}\left(0, C, C_{1}\right), g^{(1)}\left(0, C, C_{1}\right), g^{(2)}\left(0, C, C_{1}\right)$, $g^{(3)}\left(0, C, C_{1}\right), g^{(4)}\left(0, C, C_{1}\right), g^{(5)}\left(0, C, C_{1}\right):$

$$
\begin{gathered}
g^{(0)}\left(0, C, C_{1}\right)=-\frac{C \cdot C_{1}}{K\left(C, C_{1}\right)}, \\
g^{(1)}\left(0, C, C_{1}\right)=\frac{\pi}{L \cdot C \cdot K^{3}\left(C, C_{1}\right)},
\end{gathered}
$$




$$
\begin{gathered}
g^{(2)}\left(0, C, C_{1}\right)=\frac{\pi^{2} \cdot C \cdot C_{1}^{3}\left[\left(C \cdot C_{1}\right)^{2}-4\right]}{L^{2} \cdot K^{5}\left(C, C_{1}\right)}, \\
g^{(3)}\left(0, C, C_{1}\right) \\
=-\frac{\pi^{3} \cdot\left[\left(C \cdot C_{1}\right)^{4}-15 \cdot C^{2} \cdot C_{1}^{4}-2 \cdot\left(C \cdot C_{1}\right)^{2}+1\right]}{L^{3} \cdot C \cdot K^{7}\left(C, C_{1}\right)}, \\
g^{(4)}\left(0, C, C_{1}\right) \\
=\frac{\pi^{4} \cdot C \cdot C_{1}^{3}\left[4\left(C \cdot C_{1}\right)^{6}-3 C^{4} \cdot C_{1}^{6}-24\left(C \cdot C_{1}\right)^{4}\right.}{L^{4} \cdot K^{9}\left(C, C_{1}\right)} \\
+\frac{\left.36 C^{2} C_{1}^{4}+36 C^{2} \cdot C_{1}^{2}+72 C_{1}^{2}-16\right]}{L^{4} \cdot K^{9}\left(C, C_{1}\right)} \\
g^{(5)}\left(0, C, C_{1}\right) \\
+\frac{\pi^{5}\left[\left(C \cdot C_{1}\right)^{8}-150 C^{6} \cdot C_{1}^{8}-4\left(C \cdot C_{1}\right)^{6}\right.}{C \cdot L^{5} \cdot K^{11}\left(C, C_{1}\right)} \\
+\frac{525 C^{4} C_{1}^{8}+300 C^{4} \cdot C_{1}^{6}+6\left(C \cdot C_{1}\right)^{4}}{C \cdot L^{5} \cdot K^{11}\left(C, C_{1}\right)} \\
+\frac{\left.420 C^{2} \cdot C_{1}^{4}-150 C^{2} C_{1}^{4}-4\left(C \cdot C_{1}\right)^{2}+1\right]}{C \cdot L^{5} \cdot K^{11}\left(C, C_{1}\right)},
\end{gathered}
$$

where $K\left(C, C_{1}\right)=\sqrt{\left[1-\left(C \cdot C_{1}\right)^{2}\right]}$.

Using the expressions obtained above, the sixmembered segment of the Taylor series for function $g\left(x, C, C_{1}\right)$ takes the following form:

$$
g\left(x, C, C_{1}\right)=\sum_{n=0}^{5} g^{(n)}\left(0, C, C_{1}\right) \frac{x^{n}}{n !} .
$$

After integrating the segment of Taylor series (17), we obtain an approximate expression for the desired function $y\left(x, C, C_{1}, C_{2}\right)$ :

$$
y\left(x, C, C_{1}, C_{2}\right)= \pm \sum_{n=0}^{5} g^{(n)}\left(0, C, C_{1}\right) \frac{x^{n+1}}{(n+1) !}+C_{2},
$$

where $C_{1}, C_{2}$ are unknown constants that are found from the boundary conditions (14).

For numerical implementation of this task, we choose one variant of boundary conditions:

$L=1, \quad C=1.1, y(0)=0, \quad y(L)=0 ;$ (the start and finish points lie on axis $O X)$.

1) First, in the formula (18), we consider the case with the plus sign.

From the first boundary condition (14) $y(0)=0$ it follows that the second unknown constant $C_{2}$ is zero. To determine the first unknown constant $C_{1}$, it is necessary to solve an essentially nonlinear algebraic equation with respect to constant $C_{1}$. The solution of this equation was performed by numerical methods using the MathCAD application package. As a result, the following value was obtained for the first unknown constant: $C_{1}=0.385$.

Fig. 2 shows a graph $y(x)$ of the desired trajectory of the material point (boat) with the boundary conditions 1), obtained using equation (18) at $C_{1}=0.385$ and $C_{2}=0$. Here, to reduce the record, function $y(x)$ should be read as function $y(x ; 1,1 ; 0,385 ; 0)$.

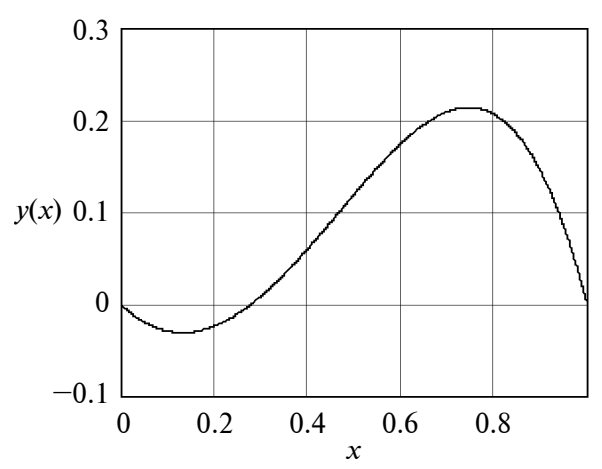

Fig. 2. The graph $y(x)$ of the desired trajectory of the material point with the boundary conditions 1 )

Let us determine the time of the boat moving along the trajectory found for this case. We use formula (7) to calculate it with the selected data of the studied problem. In other words, function $f(x)$ is selected by formula (15), function $y(x)$ is chosen by formula (18), $L=1, \quad C=1.1$, $C_{1}=0.385, C_{2}=0$. As a result of calculating integral (7), we obtain $T=2.46$ (units of time).

2) Now consider the case with the minus sign in formula (18).

The method of constructing the corresponding graph remains the same, therefore we will give only brief comments on it.

And in this case, the solution of a nonlinear algebraic equation with respect to an unknown constant $C_{1}$ gives the same result: $C_{1}=0.385$. Therefore, for this case, the graph of the desired function will have a similar form (Fig. 3), only its ordinates will have opposite signs with the same abscissas as graph in Fig. 2.

Thus, Fig. 3 shows two graphs $y_{1}(x)$ and $y_{2}(x)$ that are constructed for two functions and 
that approximate the desired function $y(x)$ with regard to the different number of members of the Taylor series. The graph $y_{1}(x)$ is a dotted curve that is plotted for a function in which five members of the Taylor series were taken into account. The graph $y_{2}(x)$ is a solid curve that is plotted for a function in which the six members of the Taylor series are accounted for. As you can see, the graphs $y_{1}(x)$ and $y_{2}(x)$ practically coincide and represent one curve. Therefore, in this case, only five members of the Taylor series should be taken into account without losing the accuracy of the approximation of the desired function $y(x)$.

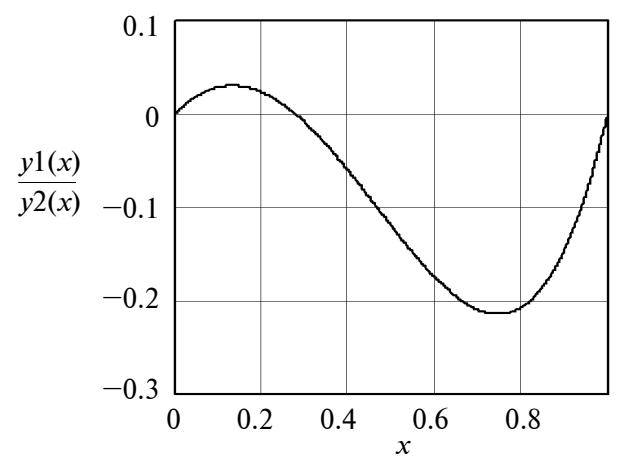

Fig. 3. Graphs $y_{1}(x)$ and $y_{2}(x)$ of the desired trajectory of the material point with the boundary conditions 2$)$ : the graph $y_{1}(x)$ is a dotted curve (five members of the Taylor series were taken into account); the graph $y_{2}(x)$ is a solid curve (six members of the Taylor series were taken into account)

Now we calculate the time of the boat moving along this trajectory, obtained with the minus sign in front of the integral in formula (18). After calculations we get a smaller result: $T=1.14$ (units of time) compared with the first.

Thus, comparing the obtained results, we can conclude that function $y(x)$ found with the plus sign in formula (18) gives the maximum value to functional (7), and the function with the minus sign is the minimum value of all motion paths that correspond to the formulation of the presented variational problem.

At the end of the paper, for illustration, we will give an example of calculating the time of a boat moving in a straight line from a point $O(0,0)$ to a point $M(L, 0)$ along the abscissa axis. In this case, the trajectory of the boat is described by function $y(x) \equiv 0$. At first glance, this trajectory should be optimal in the sense of a minimum of time spent on moving the boat from point $O(0,0)$ to point $M(L, 0)$. However, this is not the case, and the calculation results refute this assumption. Formula (7), when substituting a function into it, gives $T=1.344$ (units of time). Thus, the "shortest path" of the movement of the boat is not the "fastest" in this variational problem.

\section{Conclusions}

In this paper, a new variation problem on the brachistochrone is formulated and solved for the case of the motion of a material point (motorboat) in the horizontal one-dimensional vector field of a mobile fluid (river). The module of the velocity of a mobile fluid is given as a function of the transverse coordinate (with respect to the velocity vector of the mobile fluid). The material point moves in the specified vector field with a speed which is constant (in magnitude) but changing in direction. Using the methods of variational calculus, the differential equation of the trajectory of the material point was derived, which is not integrated explicitly. Based on the expansion of the integrand in a Taylor series, an approximate equation of the motion path of a point was obtained taking into account the given boundary conditions.

It is shown that for a sufficiently accurate approximation of the solution, it is sufficient to take into account only five members of the Taylor series.

For the chosen variant of the boundary conditions, the equations of optimal trajectories are obtained by numerical methods, along which the material point (boat) goes from the start to finish in an extreme time. In this case, the optimal trajectories for the considered function of the river velocity are oscillatory. It is shown that this variational problem has two different solutions, which differ only in sign. In this case, one solution gives a minimum of time to the functional, and the second solution gives a maximum.

Future research in this area will be aimed at finding brachistochrones when moving a material point along a certain transcendental surface without friction in a vertical gravitational field.

The development will be interesting for specialists in the field of civil and military logistics, developers of navigation equipment for high-speed maneuverable river and sea vessels that move in fast currents. 


\section{References}

[1] S.O. Gladkov and S.B. Bogdanova, "Analytical and numerical solution of the problem on brachistochrones in some general cases”, in Itogi Nauki i Tehniki. Sovremennaja Matematika i Ee Prilozhenija. Tematicheskie Obzory, vol. 145. Moscow, SU: VINITI, 2018, pp. 114-122.

[2] A.V. Zarodnyuk and O.Yu. Cherkasov, "Qualitative analysis of optimal trajectories of the point mass motion in a resisting medium and the brachistochrone problem", J. Comput. Syst. Sci. Int., vol. 54, no. 1, pp. 39-47, 2015. doi: $10.1134 / \mathrm{S} 106423071501013 \mathrm{X}$

[3] A.V. Zarodnyuk and O.Yu. Cherkasov, "A qualitative analysis of the brachistochrone problem with dry friction and maximizing the horizontal range”, Moscow Univ. Mech. Bull., vol. 71, no. 4, pp. 93-97, 2016. doi: 10.3103/S002713301604004X

[4] A.V. Zarodnyuk and O.Yu. Cherkasov, "On the maximization of the horizontal range and the brachistochrone with an accelerating force and viscous friction”, J. Comput. Syst. Sci. Int., vol. 56, no. 4, pp. 553-560, 2017. doi: $10.1134 /$ S1064230717040177

[5] A.V. Zarodnyuk and O.Yu. Cherkasov, "Support reaction in the brachistochrone problem in a resistant medium", in Dynamical Systems in Applications, Springer Proceedings in Mathematics \& Statistics, Łydź, Poland, Dec. 11-14, 2017, vol. 249, pp. 451-460. doi: 10.1007/978-3-319-96601-4_40

[6] A.S. Vondrukhov and Yu.F. Golubev, "Brachistochrone with an accelerating force", J. Comput. Syst. Sci. Int., vol. 53, no. 6, pp. 824-838, 2014, doi: 10.1134/S1064230714060124

[7] A.S. Vondrukhov and Yu.F. Golubev, "Optimal trajectories in the brachistochrone problem with an accelerating force", J. Comput. Syst. Sci. Int., vol. 54, no. 4, pp. 514-524, 2015. doi: 10.1134/S1064230715040139

[8] A.S. Vondrukhov and Y.F. Golubev, "Optimal trajectories in brachistochrone problem with Coulomb friction", J. Comput. Syst. Sci. Int., vol. 55, no. 3, pp. 341-348, 2016. doi: 10.1134/S1064230716030163

[9] A.S. Sumbatov, "The problem on a brachistochrone (classification of generalizations and some recent results)", Proc. MIPT. Ser. Mechanics, vol. 9, no. 3, pp. 66-75, 2017.

[10] R.T. Boute, "The brachistochrone problem solved geometrically: A very elementary approach", Mathematics Magazine, vol. 85, no. 3, pp. 193-199, 2012. 10.4169/math.mag.85.3.193

[11] H.W. Broer, "Bernoulli's light ray solution of the brachistochrone problem through Hamilton's eyes", Int. J. Bifurcation and Chaos, vol. 24, no. 8, 2014. doi: 10.1142/S0218127414400094

[12] O. Jeremic et al., "On the brachistochrone of a variable mass particle in general force fields", Math. Comp. Model., vol. 54, pp. 2900-2912, 2011. doi: 10.1016/j.mcm.2011.07.011

[13] V.P. Legeza, "Cycloidal pendulum with a rolling cylinder", Mechanics of Solids, vol. 47, no. 4, pp. 380-384, 2012. doi: $10.3103 /$ S0025654412040024

[14] V.P. Legeza "Efficiency of a vibroprotection system with an isochronous roller damper", Mechanics of Solids, vol. 48, no. 2, pp. 168-177, 2013. doi: 10.3103/S0025654413010088

[15] M. Levi, Classical Mechanics with Calculus of Variations and Optimal Control. AMS, Providence: Pennsylvania State University, 2014, 299 p.

[16] Y. Nishiyama, "The brachistochronic curve: The problem of quickest descent", Int. J. Pure Appl. Math., vol. 82, no. 3, pp. 409-419, 2013.

[17] A. Obradovic et al., "The brachistochronic motion of a vertical disk rolling on a horizontal plane without slip", Theor. Appl. Mech., vol. 44, no. 2, pp. 237-254, 2017. doi: 10.2298/tam171002015o

[18] R. Radulovic et al., "Analysis the brachistochronic motion of a mechanical system with nonlinear nonholonomic constraint", FME Trans., vol. 42, no. 4, pp. 290-296, 2014. doi: 10.5937/fmet1404290r

[19] R. Radulovic et al., "The brachistochronic motion of a wheeled vehicle", Nonlinear Dynamics, vol. 87, no. 1, pp. 191-205, 2017. doi: 10.1007/s11071-016-3035-3

[20] S. Salinic et al., "Brachistochrone with limited reaction of constraint in an arbitrary force field", Nonlinear Dynamics, vol. 69 , no. 1, pp. 211-222, 2012. doi: 10.1007/s11071-011-0258-1

[21] A.S. Sumbatov, "Brachistochrone with Coulomb friction as the solution of an isoperimetrical variational problem", Int. J. Non-Linear Mech., vol. 88, pp. 135-141, 2017. doi: 10.1016/j.ijnonlinmec.2016.11.002.

\section{В.П. Легеза, О.В. Атаманюк}

\section{БРАХІСТОХРОННИЙ РУХ МАТЕРІАЛЬНОЇ ТОЧКИ В ГОРИЗОНТАЛЬНОМУ ВЕКТОРНОМУ ПОЛІ РУХОМОЇ РІДИНИ}

Проблематика. Оскільки брахістохронний рух матеріальної точки в плоскому векторному полі рухомої рідини раніше не розглядався, то сформульована варіаційна задача про пошук екстремальних траєкторій у такій постановці $є$ новою і актуальною. 
Мета дослідження. Метою роботи є отримання алгебричних рівнянь екстремальних траєкторій руху, вздовж яких матеріальна точка переміщується від заданої точки старту до заданої точки фінішу за мінімальний час.

Методика реалізації. Розв'язання поставленої задачі було виконано за допомогою залучення класичних методів варіаційного числення (для отримання диференціального рівняння траєкторії руху матеріальної точки), а також із використанням рядів Тейлора (для наближеного інтегрування отриманого диференціального рівняння). Для заданого варіанту крайових умов було встановлено наближені алгебричні рівняння екстремалей руху матеріальної точки у вигляді відрізків степеневих рядів. Було проведено порівняльний аналіз часу руху як по екстремальних траєкторіях, так і по альтернативному найкоротшому шляху - по прямій, що безпосередньо сполучає дві задані точки старту і фінішу.

Результати дослідження. Показано, що розглянута варіаційна задача має два різних розв'язки, які різняться тільки знаком. При цьому тільки один розв'язок забезпечує мінімальний час руху матеріальної точки між заданими точками старту і фрінішу. Дослідженнями також встановлено, що екстремальна траєкторія брахістохронного руху точки не є прямою та має коливальний характер.

Висновки. Запропонований підхід дає змогу наперед прокладати такий логістичний маршрут матеріальної точки (моторного човна) в плоскому векторному полі рухомої рідини між заданими точками старту і фінішу, який забезпечує мінімальний час руху між ними. При цьому не обов'язково екстремальною траєкторією в цьому випадку є найкоротша лінія, яка сполучає точки старту і фрінішу.

Ключові слова: варіаційна задача; брахістохронний рух; векторне поле рухомої рідини; функціонал часу; рівняння Ейлера; крайові умови; ряд Тейлора; екстремальна траєкторія.

\section{В.П. Легеза, А.В. Атаманюк}

\section{БРАХИСТОХРОННОЕ ДВИЖЕНИЕ МАТЕРИАЛЬНОЙ ТОЧКИ В ГОРИЗОНТАЛЬНОМ ВЕКТОРНОМ ПОЛЕ ПОДВИЖНОЙ ЖИДКОСТИ}

Проблематика. Поскольку брахистохронное движение материальной точки в плоском векторном поле подвижной жидкости раньше не рассматривалось, то сформулированная вариационная задача о поиске экстремальных траекторий в такой постановке является новой и актуальной.

Цель исследования. Целью исследования является получение алгебраических уравнений экстремальных траекторий движения, вдоль которых материальная точка перемещается от заданной точки старта до заданной точки финиша за минимальное время.

Методика реализации. Решение поставленной задачи было проведено с помощью использования классических методов вариационного исчисления (для получения дифференциального уравнения траекторий движения материальной точки), а также с использованием рядов Тейлора (для приближенного интегрирования полученного дифференциального уравнения). Для заданного варианта граничных условий были установлены приближенные алгебраические уравнения экстремалей движения материальной точки в виде отрезков степенных рядов. Был проведен сравнительный анализ времени движения как по экстремальным траекториям, так и по альтернативному кратчайшему пути - по прямой, которая соединяет две заданные точки старта и финиша.

Результаты исследования. Показано, что рассмотренная вариационная задача имеет два различных решения, которые отличаются только знаком. При этом только одно решение обеспечивает минимальное время движения материальной точки между заданными точками старта и фриниша. Исследованиями также установлено, что экстремальная траектория брахистохронного движения точки не является прямой и имеет колебательный характер.

Выводы. Предложенный подход позволяет наперед прокладывать такой логистический маршрут материальной точки (моторного катера) в плоском векторном поле подвижной жидкости между заданными точками старта и финиша, который обеспечивает минимальное время движения между ними. При этом не обязательно экстремальной траекторией в этом случае будет кратчайшая линия, которая соединяет точки старта и финиша.

Ключевые слова: вариационная задача; брахистохронное движение; векторное поле подвижной жидкости; функционал времени; уравнение Эйлера; граничные условия; ряд Тейлора; экстремальная траектория.

Рекомендована Радою

факультету прикладної математики

КПI ім. Ігоря Сікорського
Надійшла до редакції

21 травня 2019 року

Прийнята до публікації 20 червня 2019 року 